\title{
Developmental Differences in Catalase Activity and Hypoxic-Hyperoxic Effects on Fluid Balance in Isolated Lamb Lungs
}

\author{
C. M. BONUCCELLI, S. PERMUTT, AND J. T. SYLVESTER
}

Division of Pulmonary and Critical Care Medicine, Department of Medicine, The Johns Hopkins University, Baltimore, Maryland 21205-2196

\begin{abstract}
The effects of hypoxia $\left(95 \% \quad \mathrm{~N}_{2} / 5 \% \mathbf{C O}_{2}\right)$ followed by hyperoxia $\left(95 \% \mathrm{O}_{2} / 5 \% \mathrm{CO}_{2}\right)$ were determined in isolated lungs of premature (gestational age 128 to 135 d) and full-term (postnatal age 0 to 5 d) lambs perfused with autologous blood $\left(100 \mathrm{~mL} \cdot \mathrm{min}^{-1} \cdot \mathrm{kg}\right.$ body weight $\left.{ }^{-1}\right)$. In full-term lungs, hypoxia-hyperoxia compared with hypoxia alone decreased pulmonary artery pressure and increased weight gain and extravascular lung water. In premature lungs, the increase in weight gain was greater and was associated with hemorrhage and increased pulmonary arterial and peak airway pressures. Papaverine eliminated reoxygenation-induced differences in pulmonary artery pressure, peak airway pressure, and weight gain in both age groups. Osmotic reflection coefficients for total protein and albumin, measured by a modification of the filtered volume technique, averaged $0.591 \pm 0.054(\mathrm{SEM})$ and $0.465 \pm 0.054$ (SEM), respectively, and were not altered by reoxygenation or age. Catalase activity in lung tissue and erythrocytes was lower in premature lambs, but there were no age-related differences in superoxide dismutase or glutathione peroxidase activities. These results demonstrate that hypoxia-hyperoxia in isolated lamb lungs increased lung weight due to edema formation in full-term lamb lungs and hemorrhage in premature lamb lungs and that this increase was greater in premature lamb lungs. We speculate that the weight gain caused by reoxygenation was due to a vasodilation-induced increase in surface area in full-term lamb lungs and a vasoconstriction-induced increase in vascular pressure in premature lamb lungs. The mediators of this developmental difference in vasomotor tone are unknown, but lower catalase activity in premature lungs suggests that hydrogen peroxide may have played a role. (Pediatr Res 33: 519-526, 1993)
\end{abstract}

\section{Abbreviations}

Paw, pulmonary airway pressure

Ppa, pulmonary arterial pressure

WW, wet weight

LB, lung blood

BFDLW, blood-free dry lung weight

EVLW, extravascular lung water

$\Delta \mathrm{W}$, weight change

Received July 16, 1991; accepted December 29, 1992.

Correspondence: J. T. Sylvester, M.D., Johns Hopkins University School of Medicine, Department of Medicine, Division of Pulmonary and Critical Care Medicine, 720 Rutland Ave., Baltimore, MD 21205-2196.

Supported by NIH Grant F32 HL07661 and an American Lung Association Pediatric Pulmonary Research Fellowship Award.
The toxic effects of $\mathrm{O}_{2}$ are mediated by $\mathrm{O}_{2}$ metabolites, such as superoxide anion, hydroxyl radical, hydrogen peroxide, and singlet $\mathrm{O}_{2}$ (1). In lung cells, several endogenous enzyme systems, including superoxide dismutase, catalase, and glutathione peroxidase, protect against damage from these metabolites. Erythrocytes contain high concentrations of these protective enzymes and therefore may also function as an endogenous defense system (2). It has been demonstrated in several species that lung antioxidant enzyme levels increase during the last 10 to $15 \%$ of gestation (3-5). This observation suggests that the lungs of fetuses born prematurely may have an increased susceptibility to $\mathrm{O}_{2}$ toxicity.

In systemic organs, toxic $\mathrm{O}_{2}$ metabolites are thought to mediate anoxia-reoxygenation injury resulting from ischemia and reperfusion (6). This type of injury also occurs in lungs (7-11). For example, Allison et al. (12) recently demonstrated that ventilation of isolated perfused dog lungs with $95 \% \mathrm{~N}_{2} / 5 \% \mathrm{CO}_{2}$ followed by $95 \% \quad \mathrm{O}_{2} / 5 \% \mathrm{CO}_{2}$ increased pulmonary vascular resistance and filtration coefficient. The increase in filtration coefficient was prevented by the xanthine oxidase inhibitor, allopurinol, suggesting that $\mathrm{O}_{2}$ radicals derived from xanthine oxidase mediated the change, as proposed for anoxia-reoxygenation injury in systemic organs (6).

The purposes of the present study were to determine whether ventilation with $95 \% \quad \mathrm{~N}_{2} / 5 \% \mathrm{O}_{2}$ followed by $95 \% \mathrm{O}_{2} / 5 \% \mathrm{CO}_{2}$ (hypoxia-hyperoxia) altered lung fluid balance in isolated lamb lungs and, if so, whether the lungs of premature animals at 85 to $90 \%$ gestation were more susceptible to this effect than those of full-term animals. Using separately perfused and ventilated right and left lungs, we assessed lung fluid balance by measurements of lung weight, peak Paw, Ppa, and EVLW in full-term and premature lambs. To assess which determinant of lung fluid balance accounted for $\mathrm{O}_{2}$-dependent differences in weight gain, we eliminated $\mathrm{O}_{2}$-dependent differences in vascular pressure by infusing the vasodilator, papaverine, and, in other experiments, measured protein osmotic reflection coefficients using a modification of the filtered volume technique. We also measured the activities of the antioxidant enzymes superoxide dismutase, catalase, and glutathione peroxidase, in lungs and erythrocytes, because incomplete development of these defenses could predispose to oxidant injury.

\section{MATERIALS AND METHODS}

The protocols described in this report were approved by the Animal Care and Use Committee of the Johns Hopkins Medical Institutions.

Effects of age on lung fluid balance. Experiments were performed in isolated lungs of premature lambs (gestational age 128 to $135 \mathrm{~d}, n=7$ ) and full-term newborn lambs (gestation 145 to 150 days, postnatal age 0 to $5 \mathrm{~d}, n=10$ ). In the former, pregnant ewes were anesthetized with chloralose $(50 \mathrm{mg} / \mathrm{kg}$ i.v. $)$ via a percutaneous jugular catheter. Supplemental chloralose was ad- 
ministered hourly to maintain anesthesia (10 mg/ $\mathrm{kg}$ i.v.). A tracheostomy was performed, and mechanical ventilation was begun with supplemental $\mathrm{O}_{2}$ at tidal volumes of $12 \mathrm{~mL} / \mathrm{kg}$ and respiratory rate of $15 \mathrm{~min}^{-1}$. A femoral artery catheter was placed for monitoring of blood pressure, arterial blood gases, and $\mathrm{pH}$. The ewes received an i.v. drip of Ringer's lactate via the jugular catheter at a rate of approximately $100 \mathrm{~mL} / \mathrm{h}$. Fetuses were delivered by midline cesarean section and placed on the table adjacent to the ewe without disturbing the umbilical circulation. The fetuses were prevented from breathing air by placing salinefilled rubber bags over their heads. Femoral arterial and venous catheters were placed. The fetuses then received heparin $(3000$ $U$ i.v.) and were killed by rapid exsanguination from the femoral artery. After exsanguination was complete, the umbilical cord was severed. The ewes were subsequently killed by bolus injection of saturated $\mathrm{KCl}(50 \mathrm{~mL}$ i.v.) while still under anesthesia.

Full-term newborn lambs were anesthetized with ketamine (25 $\mathrm{mg} / \mathrm{kg}$ intramuscularly) and chloralose $(25 \mathrm{mg} / \mathrm{kg}$ i.v.) via a percutaneous jugular or femoral venous catheter. A tracheostomy was performed, and mechanical ventilation was begun with supplemental $\mathrm{O}_{2}$ at tidal volumes of $12 \mathrm{~mL} / \mathrm{kg}$ and respiratory rate of $20 \mathrm{~min}^{-1}$. The lambs then received heparin (3000 U i.v.) and were killed by rapid exsanguination from the femoral artery. During exsanguination, the lungs were ventilated with $\mathrm{N}_{2}$ and $5 \% \mathrm{CO}_{2}$.

After exsanguination, the surgical protocol was identical for both premature and full-term lambs. A thoracotomy was performed, and the heart and lungs were removed from the chest. The bronchus to the right upper lobe, which originates above the carina, and its accompanying arteries and veins were ligated and resected to equalize right and left lung weights and to allow measurement of antioxidant enzyme activities, as described below. The right and left mainstem bronchi were cannulated separately. The heart was removed, and cannulas were placed in the right and left pulmonary arteries. The two sides of the lung were completely divided, with care taken to allow free drainage of effluent from the pulmonary veins.

The lungs were ventilated and perfused separately but simultaneously, with one lung serving as the control for the other. Ventilation was instituted in both lungs with $95 \% \mathrm{~N}_{2} / 5 \% \mathrm{CO}_{2}$, tidal volume of $6 \mathrm{~mL} / \mathrm{kg}$ body weight, respiratory rate of 20 . $\min ^{-1}$, and positive end-expiratory pressure of $4 \mathrm{~cm}$ of water, using Harvard model 665 small-animal ventilators. The perfusate was composed of autologous blood diluted with $3 \%$ dextran in Ringer's lactate to achieve a perfusate hematocrit of $20 \%$. Each lung was perfused at a rate of $50 \mathrm{~mL} \cdot \mathrm{kg}^{-1} \cdot \mathrm{min}^{-1}$ by means of a roller pump and an extracorporeal perfusion circuit consisting of a reservoir, heat exchanger, bubble filter, flow probe, and temperature probe. This flow was chosen because it approximated normal postnatal pulmonary blood flow. The perfusate temperature was maintained at $39^{\circ} \mathrm{C}$. Perfusate $\mathrm{O}_{2}$ and $\mathrm{CO}_{2}$ tensions $\left(\mathrm{PO}_{2}\right.$ and $\mathrm{PCO}_{2}$, respectively) and $\mathrm{pH}$ were measured at regular intervals using standard electrode techniques. Perfusate glucose concentration was monitored with glucose oxidase strips. Sodium bicarbonate and $50 \%$ dextrose were added to the perfusate to maintain $\mathrm{pH}$ between 7.35 and 7.45 and glucose concentration between 125 and $250 \mathrm{mg} \cdot \mathrm{dL}^{-1}$. Although this concentration of glucose is greater than that seen in sheep in vivo, our intention was to ensure an adequate glucose supply throughout the perfusion. Each lung was suspended from a Grass model F10 force transducer for continuous measurement of lung $\Delta \mathrm{W}$, and Ppa and Paw were measured continuously with Gould P50 pressure transducers. The preparation is shown schematically in Figure 1.

Ventilation with $95 \% \mathrm{~N}_{2} / 5 \% \mathrm{CO}_{2}$ was continued during a 30 min control period. After $30 \mathrm{~min}$, one lung was selected by coin toss to be ventilated with $95 \% \mathrm{O}_{2} / 5 \% \mathrm{CO}_{2}$. Perfusion was continued for $180 \mathrm{~min}$ or until perfusate volume was depleted. At the end of perfusion, the vasculature was allowed to drain until Ppa was zero. Lung WW, BFDLW, and the weights of EVLW and LB were determined using the gravimetric technique of Pearce et al. (13).

Physiologic mechanisms of edema formation. Two experiments were performed to elucidate the mechanism of $\mathrm{O}_{2}$-dependent edema formation in this preparation. First, we attempted to eliminate the effects of differences in pulmonary vascular pressures between hypoxic and hypoxic-hyperoxic lungs by using the vasodilator, papaverine. Full-term $(n=7)$ and premature $(n=11)$ lamb lungs were isolated for perfusion as described above. Papaverine $\left(0.1 \mathrm{~g} \cdot \mathrm{L}^{-1}\right.$ or $\left.3 \times 10^{-4} \mathrm{M}\right)$ was added to both perfusates before beginning perfusion. Perfusion conditions were identical to those described above except that perfusion was terminated after $130 \mathrm{~min}$.

Second, we determined the effects of hypoxia-hyperoxia on the osmotic reflection coefficients of albumin and total protein, measured as indices of vascular permeability. Reflection coefficients $(\sigma)$ were estimated using a modification of the filtered volume technique of Maron (14), as described in the Appendix. Full-term $(n=32)$ and premature $(n=16)$ lambs were anesthetized as described above. After exsanguination, the main pulmonary artery, left atrium, and trachea were cannulated, and the lungs were removed from the chest and suspended from a Grass model F10 force transducer for continuous measurement of lung weight gain. Because the lungs were not divided, they were perfused at $100 \mathrm{~mL} \cdot \mathrm{kg}^{-1} \cdot \mathrm{min}^{-1}$ and ventilated with a tidal volume of $12 \mathrm{~mL} / \mathrm{kg}$ and a respiratory rate of $20 \mathrm{~min}^{-1}$. Ppa and Paw were monitored continuously with Gould P50 pressure transducers. After a 30-min period of ventilation with $95 \% \mathrm{~N}_{2} /$ $5 \% \mathrm{CO}_{2}$, ventilation was either continued with $95 \% \mathrm{~N}_{2} / 5 \% \mathrm{CO}_{2}$ or changed to $95 \% \mathrm{O}_{2} / 5 \% \mathrm{CO}_{2}$. In full-term lungs, perfusion was continued for an additional $99.1 \pm 4.6$ (SD) min. The left atrial pressure was then raised to 15 to $20 \mathrm{~mm} \mathrm{Hg}$ by adjusting a screw clamp on the left atrial outflow tubing to achieve a high rate of transvascular fluid filtration. In premature lungs, because of high rates of spontaneous weight gain, perfusion could be continued for only $49.1 \pm 3.5 \mathrm{~min}$ (SD) before measurement of $\sigma$, and in four preparations left atrial pressure could not be elevated. During the subsequent period of steady weight gain, perfusate samples for measurement of microhematocrit and concentrations of plasma total protein, albumin, and $\mathrm{Hb}$ were removed at regular time intervals until the lung had doubled in weight or the perfusate volume was depleted. Albumin and total protein were measured spectrophotometrically using bromcresol green (Sigma Chemical Co., St. Louis, MO) and Coomassie blue G250 (BioRad Laboratories, Richmond, CA), respectively, except in five full-term lungs and one premature lung, in which total protein was measured with a refractometer (14-16). $\mathrm{Hb}$ was measured by the method of Beutler (17). All measurements were performed at least in triplicate. The osmotic reflection coefficient was estimated as the slope of the regression of $\ln \left(\mathrm{C}_{\mathrm{t}} / \mathrm{C}_{0}\right)$ versus $\ln$ $\left[\left(\mathrm{Hct}_{0}{ }^{-1}-1\right) /\left(\mathrm{Hct}_{\mathrm{t}}^{-1}-1\right)\right]$, where $\mathrm{C}_{0}$ and $\mathrm{C}_{\mathrm{t}}$ are the plasma protein concentrations at times 0 and time $t$, respectively, Hct $_{0}$ and $\mathrm{Hct}_{\mathrm{t}}$ are the hematocrits at times 0 and $\mathrm{t}$, respectively, and the intercept is set at zero (see Appendix).

To satisfy the assumptions and requirements of this technique, we eliminated preparations in which the maximum change in hematocrit was $<1.5 \%$, and the rate of fluid filtration, calculated from the initial and final hematocrits and initial perfusate volume, was $<0.2 \mathrm{~g} / \mathrm{min} \cdot \mathrm{kg}^{-1}$ body weight. Hemolysis, estimated from measurements of $\mathrm{Hb}$ concentration in whole perfusate and perfusate supernatant, was not significant in any preparation. On this basis, data from 21 full-term and 11 premature lungs were subjected to statistical analysis.

Effects of age on antioxidant enzyme activities. A 2-g sample of the right upper lobe from premature $(n=7)$ and full-term ( $n$ $=10$ ) lambs studied in the first protocol described above was removed before perfusion, homogenized in phosphate buffer $(\mathrm{pH}$ 7.8) at a wt:vol dilution of $1: 10$, and frozen at $-70^{\circ} \mathrm{C}$ for later analysis of enzyme activities. The remainder of the lobe was used to measure wet and dry weight according to the method of Pearce 


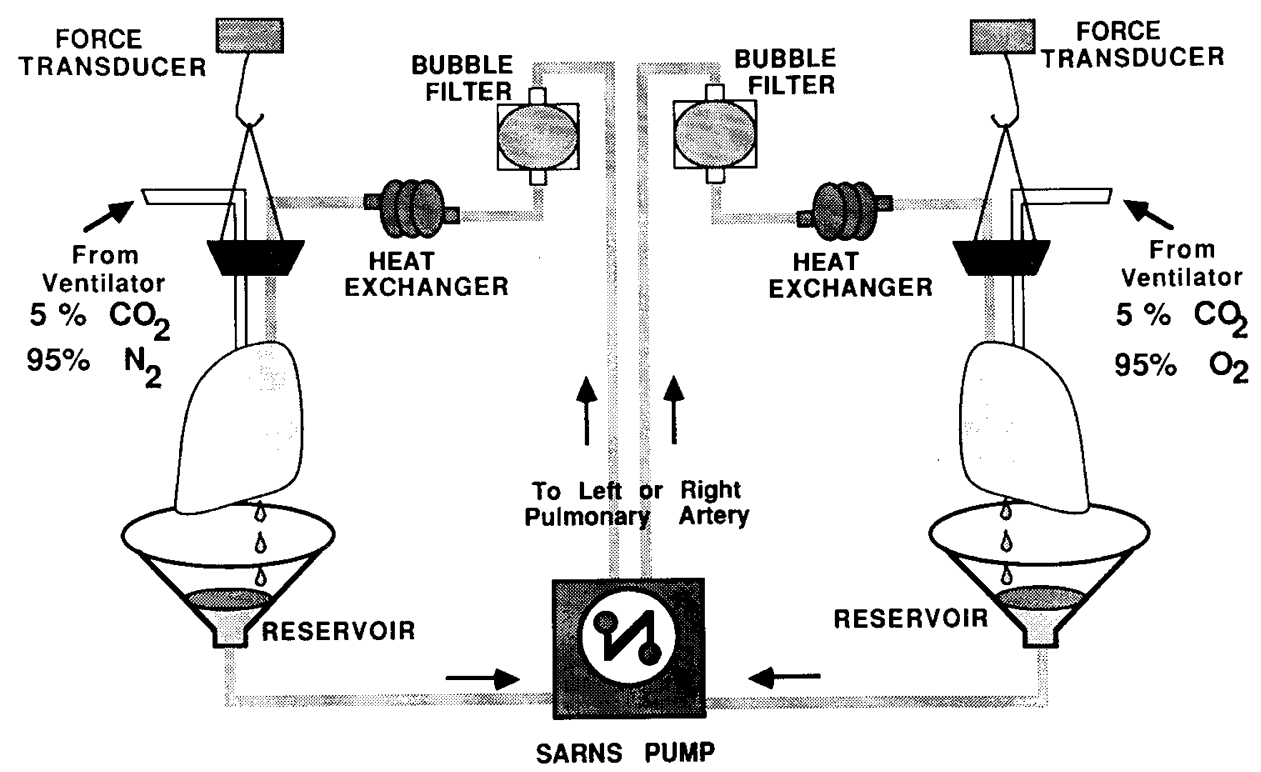

Fig. 1. Schematic diagram of the split-lung preparation: after division, each lung was suspended from a force transducer for continuous measurement of lung weight and separately perfused and ventilated.

et al. (13). Hemolysates of red blood cells from blood samples obtained at the time of exsanguination were prepared by the method of Beutler (17) and also frozen at $-70^{\circ} \mathrm{C}$ for later analysis. All analyses were done using standard spectrophotometric methods on a Bausch and Lomb Spectronic 710 spectrophotometer. Catalase activity was measured by the method of Beers and Sizer (18), superoxide dismutase by the method of McCord and Fridovich (19), and glutathione peroxidase by the method of Paglia and Valentine (20). Lung enzyme activities were corrected for blood content as estimated by tissue $\mathrm{Hb}$ and were referenced to protein measured by the method of Lowry (21). Hydroxyproline was measured by the method of Jamall et al. (22); BFDLW was also measured. Blood enzyme activities were referenced to $\mathrm{Hb}$ measured by the method of Beutler (17).

Statistical analyses. Within-group comparisons of final $\Delta \mathrm{W}$, mean Ppa, and mean Paw in perfused lungs were made using paired two-tailed $t$ tests. Within-group comparisons of gravimetric variables between perfused and unperfused lungs were made using a one-factor analysis of variance with repeated measures. For time-course experiments, comparisons within each age group were made using a two-factor (time, fraction of inspired $\mathrm{O}_{2}$ ) analysis of variance for repeated measures on both factors. Comparisons of $\mathrm{O}_{2}$-dependent differences between age groups were made using a two-factor (time, age) split-plot analysis of variance. Unpaired, two-tailed $t$ tests were used to compare enzyme activities between age groups. Two-factor (age, fraction of inspired $\mathrm{O}_{2}$ ) analysis of variance was used to compare reflection coefficients. Unless stated otherwise, values presented in the text are means $\pm \mathrm{SD}$.

\section{RESULTS}

Effects of age on lung fluid balance. In full-term lamb lungs, perfusate $\mathrm{PO}_{2}, \mathrm{PCO}_{2}$, and $\mathrm{pH}$ during the experimental period averaged $44.3 \pm 6.0 \mathrm{kPa}(333 \pm 45 \mathrm{~mm} \mathrm{Hg}), 3.2 \pm 0.4 \mathrm{kPa}(24$ $\pm 3 \mathrm{~mm} \mathrm{Hg}$ ), and $7.38 \pm 0.03$, respectively, in hypoxic-hyperoxic lungs and $1.6 \pm 0.5 \mathrm{kPa}(12 \pm 4 \mathrm{~mm} \mathrm{Hg}), 3.0 \pm 0.3 \mathrm{kPa}(23 \pm$ $2 \mathrm{~mm} \mathrm{Hg}$ ), and $7.38 \pm 0.07 \mathrm{~mm} \mathrm{Hg}$, respectively, in hypoxic lungs. As shown in Table 1, perfusion of full-term lungs increased WW and blood weight in both the hypoxic and hypoxic-hyperoxic groups, but EVLW was increased only in hyperoxic lungs. Hypoxic-hyperoxic lungs had higher WW than hypoxic lungs due to higher EVLW. LB weights were not different. Compared with hypoxic lungs, cumulative weight gain during the experimental period was greater in lungs exposed to hypoxia-hyperoxia
Table 1. Weight gain, gravimetrics, and mean pressures in fullterm lungs (means $\pm S E M, n=10$ )*

\begin{tabular}{|c|c|c|c|}
\hline & \multirow[b]{2}{*}{ Unperfused } & \multicolumn{2}{|c|}{ Perfused } \\
\hline & & Hypoxia & $\begin{array}{l}\text { Hypoxia- } \\
\text { hyperoxia }\end{array}$ \\
\hline$\Delta \mathrm{W} / \mathrm{BFDLW}(\mathrm{g} / \mathrm{g})$ & & $3.05(0.89)$ & $4.21(1.21) \dagger$ \\
\hline$\overline{\mathrm{P}} \mathrm{pa}(\mathrm{mm} \mathrm{Hg})$ & & $37.9(5.5)$ & $29.1(4.4) \dagger$ \\
\hline$\overline{\mathrm{P}} \mathrm{aw}(\mathrm{mm} \mathrm{Hg})$ & & $11.1(2.3)$ & $11.6(1.9)$ \\
\hline WW/BFDLW $(\mathrm{g} / \mathrm{g})$ & $5.52(0.34)$ & $8.88(0.86) \ddagger$ & $10.36(1.17) \dagger t$ \\
\hline EVLW/BFDLW $(\mathrm{g} / \mathrm{g})$ & $3.67(0.22)$ & $3.87(0.36)$ & $4.82(0.47) \dagger \ddagger$ \\
\hline LB/BFDLW $(\mathrm{g} / \mathrm{g})$ & $0.76(0.21)$ & $4.05(0.62) \ddagger$ & $4.56(0.98) \ddagger$ \\
\hline
\end{tabular}

$* \Delta \mathrm{W}$, Cumulative weight gain over the course of perfusion; $\bar{P}$ pa and $\overline{\mathrm{P}}$ aw, mean pulmonary arterial and peak airway pressures during the experimental period.

$\dagger p<0.05$ compared with hypoxia.

$\$ p<0.05$ compared with unperfused.

Table 2. Weight gain, gravimetrics, and mean pressures in premature lungs (means $\pm S E M, n=7$ )*

\begin{tabular}{|c|c|c|c|}
\hline & \multirow[b]{2}{*}{ Unperfused } & \multicolumn{2}{|c|}{ Perfused } \\
\hline & & Hypoxia & $\begin{array}{l}\text { Hypoxia- } \\
\text { hyperoxia }\end{array}$ \\
\hline$\Delta \mathrm{W} / \mathrm{BFDLW}(\mathrm{g} / \mathrm{g})$ & & $5.91(1.85)$ & $9.92(3.15) \dagger$ \\
\hline$\overline{\mathrm{P}} \mathrm{pa}(\mathrm{mm} \mathrm{Hg})$ & & $45.3(3.8)$ & $44.2(6.0)$ \\
\hline Paw (mm Hg) & & $20.4(3.3)$ & $21.9(3.3)$ \\
\hline WW/BFDLW $(\mathrm{g} / \mathrm{g})$ & $12.74(0.11)$ & $17.2(2.37) \ddagger$ & $20.63(2.49) \dagger+$ \\
\hline EVLW/BFDLW (g/g) & $10.91(0.42)$ & $8.67(0.32) \ddagger$ & $9.03(0.31) \ddagger$ \\
\hline LB/BFDLW $(\mathrm{g} / \mathrm{g})$ & $0.79(0.04)$ & $7.50(3.0) \$$ & $11.20(2.78) \dagger \ddagger$ \\
\hline
\end{tabular}

* Abbreviations are the same as in Table 1 .

$\dagger p<0.05$ compared with hypoxia.

$\ddagger p<0.05$ compared with unperfused.

despite lower mean Ppa. There were no differences in mean peak Paw.

In premature lambs, perfusate $\mathrm{PO}_{2}, \mathrm{PCO}_{2}$, and $\mathrm{pH}$ during the experimental period averaged $44.0 \pm 6.1 \mathrm{kPa}(331 \pm 46 \mathrm{~mm}$ $\mathrm{Hg}), 2.8 \pm 0.4 \mathrm{kPa}(21 \pm 3 \mathrm{~mm} \mathrm{Hg})$, and $7.36 \pm 0.05$, respectively, in reoxygenated lungs and $1.6 \pm 0.5 \mathrm{kPa}(12 \pm 4 \mathrm{~mm} \mathrm{Hg}), 2.8$ $\pm 0.3 \mathrm{kPa}(21 \pm 2 \mathrm{~mm} \mathrm{Hg})$, and $7.37 \pm 0.04$, respectively, in hypoxic control lungs. As shown in Table 2, perfused premature lungs had higher WW and LB than unperfused lungs; however, 
EVLW was decreased by perfusion, possibly due to absorption of intraalveolar fetal lung fluid. Hypoxic-hyperoxic lungs had higher WW than hypoxic lungs. This difference was due to higher LB rather than higher EVLW and was consistent with the frequent occurrence of bloody tracheal edema and subpleural collections of blood, indicating hemorrhage. These hemorrhagic phenomena occurred in four of seven reoxygenated and one of seven hypoxic premature lungs but were not observed in fullterm lungs. Cumulative lung weight gain was greater in lungs exposed to hypoxia-hyperoxia. There were no differences in mean Ppa or Paw.

A comparison of Tables 1 and 2 reveals that WW and EVLW of the unperfused right upper lobes were greater in premature lambs, probably because of the large volume of intraalveolar water in these lungs. Comparison of the other results in Tables 1 and 2 is difficult, however, because full-term lungs were perfused longer than premature lungs ( $139.3 \pm 17.7$ min versus 92.9 $\pm 10.0 \mathrm{~min}, p<0.05$ ). To allow comparison between age groups, we examined the time courses of $\Delta \mathrm{W}, \mathrm{Ppa}$, and Paw in lungs that completed $100 \mathrm{~min}$ of perfusion. On this basis, three fullterm and two premature lungs were excluded. As shown in Figure 2 , lung weight gain increased steadily over the course of perfusion in both full-term and premature lambs and was accelerated by hyperoxia. This $\mathrm{O}_{2}$-dependent effect was greater in premature lambs. Peak Paw in full-term lungs averaged $9.5 \mathrm{~mm} \mathrm{Hg}$, was not altered by hyperoxia, and did not change over time. In premature lungs, peak Paw was higher and increased at the end of perfusion in lungs exposed to hypoxia-hyperoxia. The timecourse differences in Ppa were more complicated. In full-term lambs, Ppa exhibited a progressive decline, which was accelerated in the reoxygenated lung. In premature lungs, a similar trend

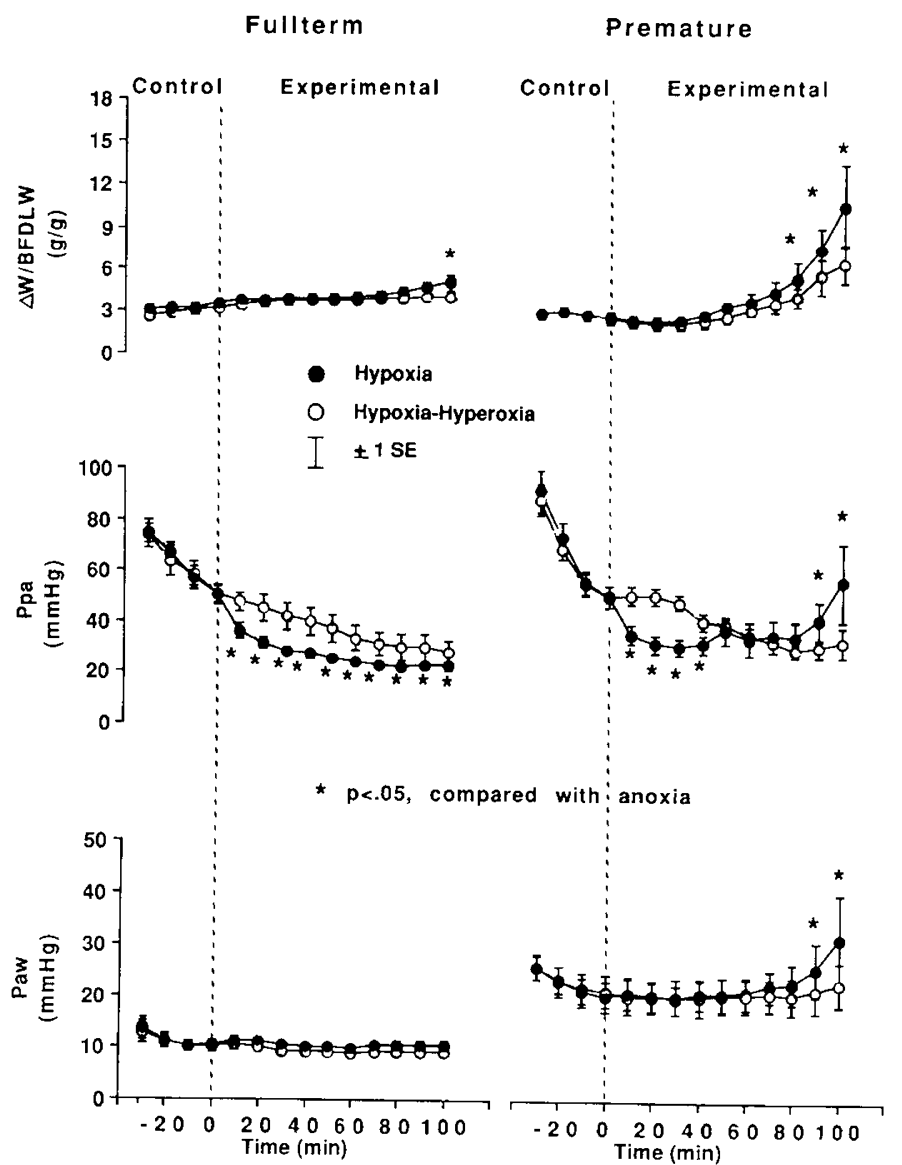

Fig. 2. Time course of lung weight gain normalized to BFDLW $(\Delta W /$ $B F D L W), \mathrm{Ppa}$, and Paw in full-term (left) and premature (right) lungs exposed to $95 \% \mathrm{~N}_{2} / 5 \% \mathrm{CO}_{2}$ (hypoxia) or $95 \% \mathrm{~N}_{2} / 5 \% \mathrm{CO}_{2}$ followed by $95 \% \mathrm{O}_{2} / 5 \% \mathrm{CO}_{2}$ (hypoxia-hyperoxia). was seen for the first $40 \mathrm{~min}$ of the experimental period, but thereafter Ppa rose in the hyperoxic lung.

Figure 3 directly compares the time course of the $\mathrm{O}_{2}$-dependent differences in weight gain, Ppa, and peak Paw for premature and full-term lungs. For each variable, the change caused by hypoxiahyperoxia was greater in prematures.

Physiologic mechanisms of edema formation. As shown in Figure 4, papaverine eliminated $\mathrm{O}_{2}$-dependent differences in Ppa, $\Delta \mathrm{W}$, and Paw in both full-term and premature lungs. In fullterm lambs, papaverine-treated lungs had lower vascular pressures than untreated lungs and did not gain weight during the experimental period (Figs. 2 and 4). In contrast, lung weight gain in papaverine-treated premature lungs exceeded that in untreated lungs despite markedly lower vascular pressures in the papaverine-treated group $[\mathrm{Ppa}=24.7 \pm 2.8$ versus $44.8 \pm 6.9 \mathrm{~mm} \mathrm{Hg}$ (SEM), $p<0.001]$.

Figure 5 shows the regression analysis of $\ln \left(\mathrm{C}_{\mathrm{t}} / \mathrm{C}_{0}\right)$ versus $\ln$ $\left[\left(\mathrm{Hct}_{0}^{-1}-1\right) /\left(\mathrm{Hct}_{\mathrm{t}}^{-1}-1\right)\right]$ in a representative experiment. For all lungs, the correlation coefficient $\left(r^{2}\right)$ for these regressions averaged $0.913 \pm 0.025$ (SEM) for albumin and $0.903 \pm 0.026$ (SEM) for total protein. Table 3 shows the mean osmotic reflection coefficients for full-term and premature lungs calculated from the slopes of these regressions. There were no $\mathrm{O}_{2-}$ or agedependent differences in either $\sigma_{\text {alb }}$ or $\sigma_{\text {tp }}$. As expected, $\sigma_{\text {alb }}$ was lower than $\sigma_{\mathrm{tp}}[0.465 \pm 0.054$ versus $0.591 \pm 0.054$ (SEM), $p<$ $0.001]$.

Effect of age on antioxidant enzyme activities. Tables 4 and 5 show catalase, glutathione peroxidase, and superoxide dismutase activities for lung tissue and erythrocytes, respectively. Catalase activity in premature lungs was about half of that in full-term lungs. There were no age-related differences in lung superoxide dismutase or glutathione peroxidase activities. Results were similar whether normalized to hydroxyproline concentration, pro-

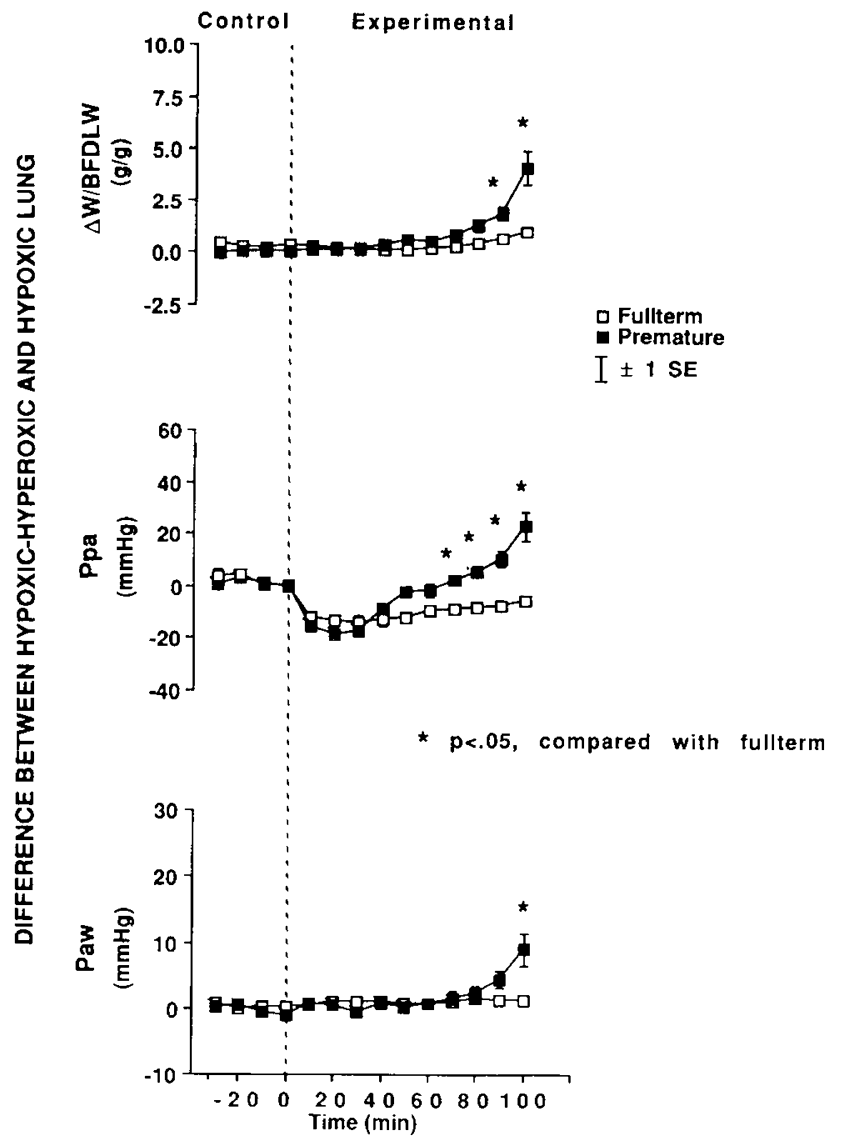

Fig. 3. Comparison of the paired differences in lung weight gain $(\Delta W /$ $B F D L W$ ), $\mathrm{Ppa}$, and Paw between the reoxygenated and hypoxic lungs of full-term and premature lambs. 


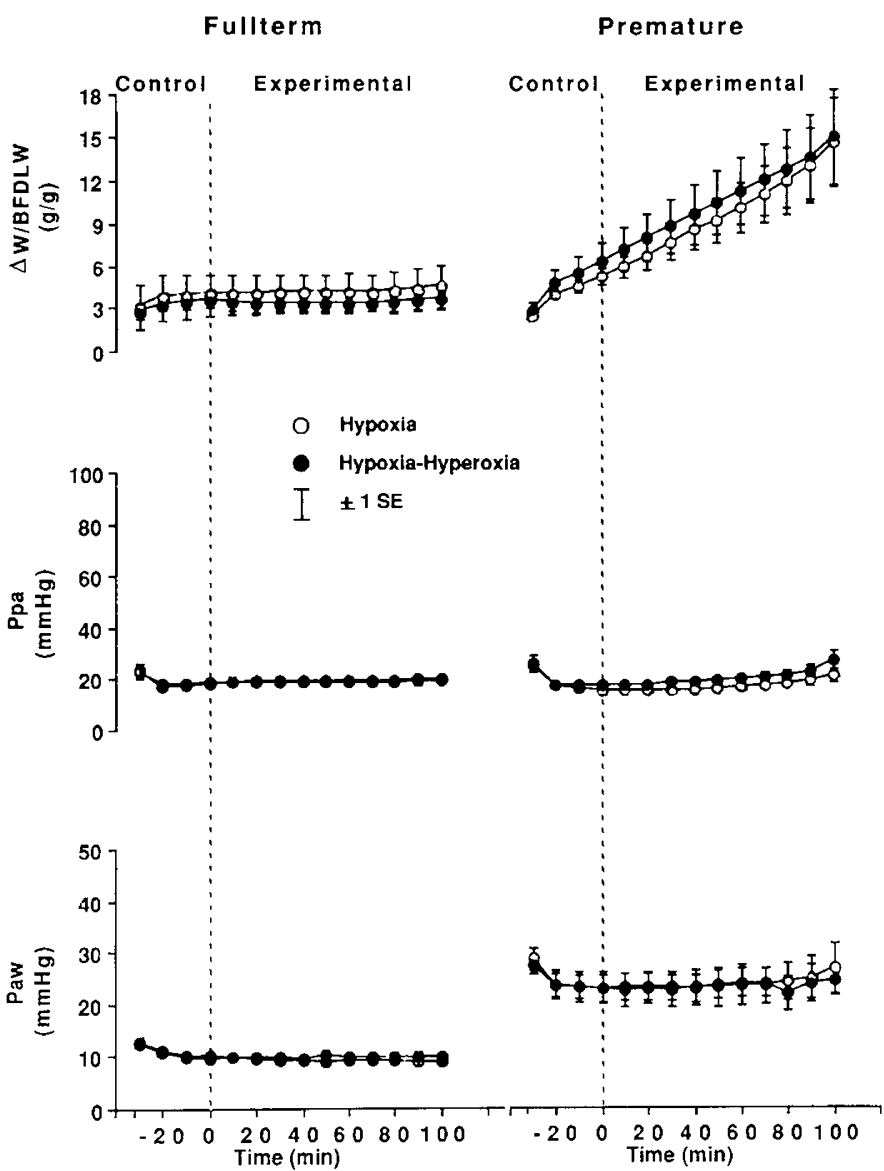

Fig. 4. Time course of lung weight gain normalized to BFDLW $(\Delta W /$ $B F D L W)$, Ppa, and Paw in full-term (left) and premature (right) lungs treated with $0.1 \mathrm{~g} / \mathrm{L}$ papaverine and exposed to hypoxia or hypoxiahyperoxia.

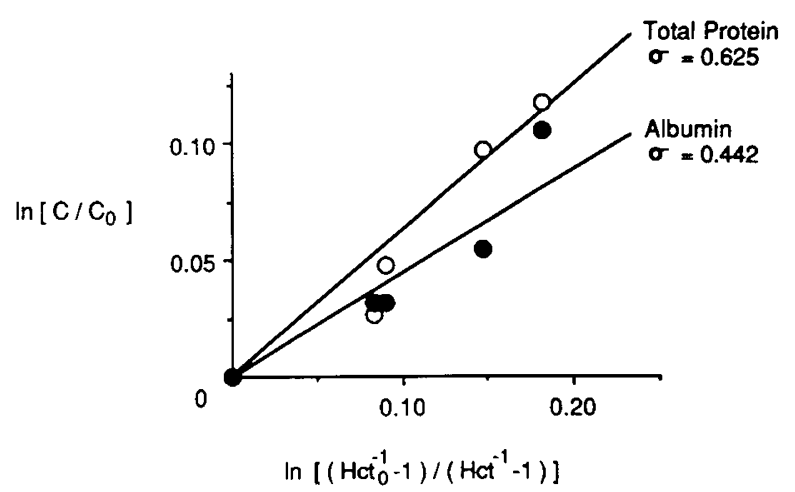

Fig. 5. Example of a regression analysis of $\ln \left(\mathrm{C}_{t} / \mathrm{C}_{0}\right)$ versus $\ln \left[\left(\mathrm{Hct}_{0}{ }^{-1}\right.\right.$ $\left.-1) /\left(\mathrm{Hct}_{\mathrm{t}}{ }^{-1}-1\right)\right]$ for a reoxygenated premature lung. The slopes of these lines represent the osmotic reflection coefficients for total protein and albumin, respectively.

Table 3. Osmotic reflection coefficients for albumin and total protein in premature and full-term lungs (means \pm SEM)

\begin{tabular}{llcc}
\hline Protein & Group & Hypoxia & $\begin{array}{c}\text { Hypoxia- } \\
\text { hyperoxia }\end{array}$ \\
\hline Albumin & Full-term & $0.418 \pm 0.05$ & $0.516 \pm 0.15$ \\
& Premature & $0.479 \pm 0.10$ & $0.441 \pm 0.15$ \\
Total protein & Full-term & $0.588 \pm 0.09$ & $0.636 \pm 0.10$ \\
& Premature & $0.592 \pm 0.14$ & $0.507 \pm 0.12$ \\
\hline
\end{tabular}

Table 4. Lung homogenate antioxidant enzyme activity (corrected for blood content)*

\begin{tabular}{lcc}
\hline Enzyme activity & Premature & Full-term \\
\hline Catalase & & \\
IU/mg protein & $6.8 \pm 2.8$ & $15.2 \pm 6.1 \dagger$ \\
IU/mg HP & $381 \pm 78$ & $726 \pm 80 \dagger$ \\
IU/g BFDLW & $1395 \pm 91$ & $5568 \pm 112 \dagger$ \\
Glutathione peroxidase & & \\
IU/mg protein & $0.102 \pm 0.025$ & $0.155 \pm 0.036$ \\
IU/mg HP & $3.2 \pm 1.0$ & $6.6 \pm 5.0$ \\
IU/g BFDLW & $2.27 \pm 0.13$ & $3.17 \pm 1.0$ \\
Superoxide dismutase & & \\
IU/mg protein & $326 \pm 100$ & $255 \pm 48$ \\
IU/mg HP & $7.7 \pm 2.1$ & $6.3 \pm 1.2$ \\
IU/g BFDLW & $2729 \pm 532$ & $2661 \pm 174$ \\
\hline
\end{tabular}

* Values are means \pm SEM. HP, hydroxyproline.

$\dagger p<0.05$ compared with premature.

Table 5. Erythrocyte antioxidant enzyme activity (means \pm SEM)

\begin{tabular}{lcc}
\hline Enzyme activity (IU/g/Hb) & Premature & Full-term \\
\hline Catalase & $4234 \pm 459$ & $6934 \pm 694^{*}$ \\
Glutathione peroxidase & $26.8 \pm 3.4$ & $29.7 \pm 2.1$ \\
Superoxide dismutase & $1522 \pm 654$ & $1418 \pm 452$ \\
\hline
\end{tabular}

$* p<0.05$ compared with premature.

tein concentration, or BFDLW. In erythrocytes (Table 5), catalase activity was also lower in premature lungs. Again, there were no age-related differences in the activities of superoxide dismutase or glutathione peroxidase.

\section{DISCUSSION}

The first purpose of this study was to determine whether hypoxia-hyperoxia altered lung fluid balance in isolated lamb lungs. As shown in Figures 2 and 3 and Table 1, weight gain and EVLW were higher in reoxygenated full-term lungs. Thus, relative to hypoxia alone, hypoxia-hyperoxia caused pulmonary edema in this age group.

Ppa progressively decreased during the control period, presumably due to progressive vasodilation. The cause of this vasodilation is unknown. During the experimental period, Ppa was lower in the hypoxic-hyperoxic group (Fig. 2). Possible explanations for this difference include $\mathrm{O}_{2}$-mediated release of vasodilating substances (23) and reversal of hypoxic vasoconstriction. The latter seems unlikely, inasmuch as severe steady state hypoxia did not cause vasoconstriction in previous studies of lamb lungs (24). With respect to the former, it was found that oxygenation of fetal lungs caused release of bradykinin (25) and that bradykinin could secondarily induce release of prostacyclin, a potent pulmonary vasodilator (26). Whether this occurred in our fullterm lungs is unknown. These effects of reoxygenation on Ppa differ from those observed by Allison et al. (6) in isolated lungs of adult dogs, in which reoxygenation caused an increase in pulmonary vascular resistance. This difference may be related to species or age.

The occurrence of a greater amount of EVLW in association with lower pressures suggests that, in full-term lungs, hypoxiahyperoxia increased vascular surface area or permeability. This suggestion is consistent with the observation of Allison et al. (6) that reoxygenation of hypoxic dog lungs increased the filtration coefficient.

Premature lungs showed a vascular response similar to that of full-term lungs during the early part of the experimental period, in that reoxygenation accelerated the decrease in Ppa (Fig. 2); however, this was followed by an increase in Ppa, so that by 90 min, pressures in the hyperoxic lungs exceeded those in the hypoxic lungs. This late increase in Ppa was associated with 
higher weight gain, indicating that, in this age group, hydrostatic forces may have contributed to the gain in weight.

Gravimetric analysis showed that the higher weight gain in reoxygenated premature lungs, unlike full-term lungs, was associated with higher LB weight (Table 2), suggesting hemorrhage or increased vascular volume. The former seems more likely for two reasons. First, premature lungs became obviously hemorrhagic during perfusion, as manifested by blood in tracheal edema fluid and in subpleural collections. These phenomena were not observed in full-term lungs. Because erythrocytes were used as the intravascular marker in the gravimetric analysis (18), hemorrhage would cause underestimation of EVLW. Second, before gravimetric analysis was performed, perfusate was allowed to drain from the lung until vascular pressure equalled zero. Thus, the data suggest that, in premature lungs, reoxygenation accelerated weight gain by increasing hemorrhage.

The greater hemorrhage seen in reoxygenated premature lungs implies an increase in permeability; however, because Ppa was also higher in reoxygenated lungs, the weight gain induced by hypoxia-hyperoxia could also be due to increased vascular pressure or surface area. To help distinguish among these possibilities, we performed two additional experiments. First, to evaluate the role of vascular pressure, we eliminated differences in vascular pressures between reoxygenated and control lungs by treating the lungs with a vasodilator. Second, to evaluate the role of permeability, we measured reflection coefficients for albumin and total protein.

Papaverine directly relaxes vascular smooth muscle, possibly by interfering with calcium influx (15). This nonspecific vasodilator has been used previously to evaluate the effects of changes in vascular tone on lung fluid balance. In full-term lungs not receiving papaverine, as described above, hypoxia-hyperoxia decreased Ppa and increased weight gain relative to hypoxia alone, suggesting increased surface area or permeability. In full-term lungs treated with papaverine, these $\mathrm{O}_{2}$-dependent differences (Fig. 4) were eliminated. These results suggest that the $\mathrm{O}_{2-}$ dependent increase in weight gain seen in untreated lungs (Fig. 2) was related to the $\mathrm{O}_{2}$-dependent decrease in vascular pressure. Because surface area is more likely than permeability to increase with a decrease in pressure, these findings imply that the weight gain induced by reoxygenation was due to increased surface area. However, Ppa in papaverine-treated lungs were much lower than in untreated lungs $(18.5 \pm 0.9$ versus $33.5 \pm 5.0 \mathrm{~mm} \mathrm{Hg}, p<$ 0.005 ), and significant weight gain did not occur during the experimental period (Fig. 4). This indicates that, in full-term lungs, papaverine may have lowered vascular pressures below the threshold necessary for edema formation, making it impossible to infer changes in either surface area or permeability.

In premature lungs, papaverine greatly reduced Ppa and eliminated the $\mathrm{O}_{2}$-dependent differences in Ppa and weight gain (Fig. 4). This result is consistent with the possibility that, in untreated premature lungs, reoxygenation increased weight gain by increasing the transvascular hydrostatic pressure gradient; however, during the control period, papaverine-treated premature lungs had greater weight gains than untreated premature lungs despite lower vascular pressures (Figs. 2 and 4), suggesting that papaverine itself may have been injurious. This possibility is consistent with the findings of Maron et al. (28), who recently reported that papaverine decreased the osmotic reflection coefficient for total protein in isolated dog lobes. This complicated the interpretation of our results.

To assess more directly whether the alterations in lung fluid balance caused by hypoxia-hyperoxia were due to differences in permeability, we measured protein reflection coefficients for total protein and albumin, using a modification (see Appendix) of the filtered volumes technique described by Maron (14). In full-term lungs, reflection coefficients for total protein and albumin averaged $0.613 \pm 0.068$ and $0.469 \pm 0.073$ (SEM), respectively. These values are less than those reported in intact mature sheep ( 0.89 and 0.84 , respectively), in which reflection coefficients were assessed using lymph to plasma protein concentration ratios under conditions of high filtration rates (16). These inconsistencies seem unlikely to be due to differences in technique, because it has been demonstrated that the osmotic reflection coefficients measured by the filtered volume technique did not differ significantly from those measured by the ratio of lymph to plasma protein concentrations (29). It seems more likely that the difference was due to an increase in permeability that may have occurred as a result of extracorporeal reperfusion (7) or hypoxic exposure.

As shown in Table 3, we did not find differences in osmotic reflection coefficients for total protein or albumin between the hypoxic and hypoxic-hyperoxic groups. These findings, in combination with those described above, indicate that the effects of hypoxia-hyperoxia in full-term lungs were mediated by changes in vascular surface area and not by changes in permeability or vascular pressure.

Based on our observations of hemorrhage in premature lungs, we anticipated that reflection coefficients would be lower in this age group, particularly after reoxygenation. Surprisingly, this was not the case (Table 3 ). This result suggests that the alterations in lung fluid balance caused by reoxygenation in premature lungs were due not to increased permeability, but to increased intravascular pressure, which in turn led to hemorrhage and edema formation. It should be noted, however, that high rates of spontaneous weight gain in premature lungs forced us to measure reflection coefficients $49.1 \pm 3.5 \mathrm{~min}$ into the experimental period, as compared with $99.1 \pm 4.6 \mathrm{~min}$ in full-term lungs. This time may have been insufficient for differences in permeability between control and reoxygenated premature lungs to develop (Figs. 2 and 3). Thus, a reoxygenation-induced increase in permeability cannot be excluded.

The second purpose of our study was to determine whether lungs of premature lambs were more susceptible to anoxiareoxygenation injury than those of full-term lambs. The two age groups are directly compared in Figure 3, which demonstrates that reoxygenation-induced changes in lung weight gain, Ppa, and Paw were greater in premature than in full-term lungs. These age-related differences suggest that prematurity increased susceptibility to the effects of hypoxia-hyperoxia in this model.

There are at least two possible explanations for this increase in susceptibility. First, interstitial pressure may have been lower in premature lung. As noted above, premature lungs had higher peak Paw than full-term lungs despite equal end-expiratory pressures and equivalent tidal volumes. This difference was undoubtedly due to lower surfactant activity and higher lung water in the premature lambs. Because of mechanical interdependence, higher Paw (and therefore transpulmonary pressure) may have resulted in lower interstitial pressures, causing greater filtration or hemorrhage at any level of vascular pressure and potentiating the effects of possible increases in endothelial surface area or permeability. Furthermore, increased epithelial permeability in premature lungs (25) may have favored movement of interstitial fluid into the alveolar spaces, thereby ameliorating the tendency for interstitial pressure to increase with edema formation. We do not know whether these events occurred.

Second, there may have been greater production of toxic $\mathrm{O}_{2}$ metabolites or deficient antioxidant defense mechanisms in premature lungs. We know of no evidence to suggest that production of toxic $\mathrm{O}_{2}$ metabolites is greater in premature than full-term lungs; however, Frank and others (3-5) have reported in several species that activities of lung catalase, superoxide dismutase, and glutathione peroxidase do not develop until the last 10 to $15 \%$ of gestation. Moreover, Ripalda et al. (30) reported that catalase and glutathione peroxidase activities in human erythrocytes increased with gestational age, whereas superoxide dismutase activity did not change. Because erythrocytes can scavenge $\mathrm{O}_{2}$ radicals (31) and decrease oxidant-induced injury in isolated perfused lungs (32), these results suggest that the ability of erythrocytes to 
act as an endogenous antioxidant defense system may also be a function of gestational age.

As shown in Table 4, we found that catalase activity in premature lungs was about half that in full-term lungs (6.8 versus $15.2 \mathrm{IU} / \mathrm{mg}$ protein). These differences persisted when activities were expressed relative to hydroxyproline concentration or BFDLW. There were no differences in lung superoxide dismutase or glutathione peroxidase activities. Erythrocytes showed a similar pattern (Table 5). These findings raise the possibility that lower lung and erythrocyte catalase activities may have contributed to the increased susceptibility to hypoxia-hyperoxia in premature lungs. Hydrogen peroxide, which is scavenged by catalase, has been shown to cause vasoconstriction and increase vascular permeability in isolated rabbit lungs $(33,34)$. The vasoconstriction induced by hydrogen peroxide may be due to release of thromboxane (33), which has been implicated as a mediator of spontaneous injury in isolated sheep lungs (35), or to inhibition of release of prostacyclin (36), which is thought to be the major vasodilating modulator of the neonatal pulmonary vasculature (37). Further investigation will be required to determine the role of hydrogen peroxide in this model.

\section{REFERENCES}

1. Freeman BA, Crapo JD 1982 Biology of disease: free radicals and tissue injury. Lab Invest 47:412-426

2. Schwartz E, Gill FM 1983 Hematology of the newborn. In: Williams WJ, Beutler E, Ersler AJ, Lichtman MA (eds) Hematology. McGraw-Hill, New York, pp 37-47

3. Frank L, Groseclose EE 1984 Preparation for birth into an oxygen-rich environment: the antioxidant enzymes in the developing rabbit lung. Pediatr Res 18:240-244

4. Gerden E, Tyden O, Eriksson UJ 1985 The development of antioxidant enzymatic defense in the perinatal rat lung: activities of superoxide dismutase, glutathione peroxidase, and catalase. Pediatr Res 19:687-691

5. Frank L, Sosenko IRS 1987 Development of lung antioxidant enzyme systems in late gestation: possible implications for the prematurely born infant. $\mathbf{J}$ Pediatr 110:9-14

6. McCord JM 1985 Oxygen-derived free radicals in postischemic tissue injury. New Engl J Med 312:159-163

7. Pearse DB, Brower RG, Adkinson Jr NF, Sylvester JT 1989 Spontaneous injury in isolated sheep lungs: role of perfusate leukocytes and platelets. $\mathbf{J}$ Appl Physiol 66:1287-1296

8. Barie PS, Hakim TS, Malik AB 1981 Effect of pulmonary artery occlusion and reperfusion on extravascular fluid accumulation. J Appl Physiol 50:102-106

9. Johnson RL, Cassidy SS, Haynes M, Reynolds RL, Schulz W 1981 Microvascular injury distal to unilateral pulmonary edema occlusion. J Appl Physiol 134:752-756

10. Bishop MJ, Boatman ES, Ivey TD, Jordan JP, Chaney FW 1986 Reperfusion of ischemic dog lung results in fever, leukopenia, and lung edema. J Appl Physiol 134:752-756

11. Jackson RM, Veal CF, Alexander CB, Fulmer JD 1988 Reexpansion pulmonary edema: a potential role for free radicals in the pathogenesis. Am Rev Respir Dis 137:1165-1171

12. Allison RC, Kyle J, Adkins WK, Prasad VR, McCord JM, Taylor AE 1990 Effect of ischemia-reperfusion or hypoxia on lung vascular permeability and resistance. J Appl Physiol 69:597-603

13. Pearce ML, Yamashita BA, Beazell J 1965 Measurement of pulmonary edema. Circ Res 16:482-488

14. Maron MB 1982 Differential effects of histamine on protein permeability in dog lung and forelimb. Am J Physiol 242:H565-H572

15. Huddart H, Saad KHM 1980 Papaverine-induced inhibition of electrical and mechanical activity and calcium movements of rat ileal smooth muscle. J Exp Biol 86:99-114

16. Parker RE, Roselli RJ, Brigham KL 1985 Effects of prolonged elevated microvascular pressure on lung fluid balance in sheep. J Appl Physiol 58:869874

17. Beutler E 1984 The preparation of red cells for assay. In: Beutler E (ed) Red Cell Metabolism, A Manual of Biochemical Methods. Grune and Stratton, New York, pp 8-12

18. Beers RF, Sizer IW 1952 A spectrophotometric method for measuring the breakdown of hydrogen peroxide by catalase. J Biol Chem 195:133-140

19. McCord JM, Fridovich I 1969 Superoxide dismutase: an enzymic function for erythrocuprein. J Biol Chem 244:6049-6055

20. Paglia DE, Valentine WN 1967 Studies on the quantitative and qualitative characterization of erythrocyte glutathione peroxidase. J Lab Clin Med 70:158-169

21. Lowry OH, Rosebrough NJ, Farr L, Randall RJ 1951 Protein measurement with the Folin phenol reagent. J Biol Chem 193:265-275

22. Jamall IS, Finelli VN, Que Hee SS 1981 A simple method to determine nanogram levels of 4-hydroxyproline in biological tissues. Anal Biochem 112:70-75
23. Harlan JM, Callahan KS 1984 Role of hydrogen peroxide in the neutrophilmediated release of prostacyclin from cultured endothelial cells. J Clin Invest $74: 442-448$

24. Gordon JB, Tod ML, Wetzell RC, McGeady ML, Adkinson NF, Sylvester JT 1988 Age-dependent effects of indomethacin on hypoxic vasoconstriction in neonatal lamb lungs. Pediatr Res 23:580-584

25. Heymann MA, Rudolph AM, Nies AS, Melmon KL 1969 Bradykinin production associated with oxygenation of the fetal lamb. Circ Res 25:521-534

26. Heymann MA 1987 Postnatal regulation of the pulmonary circulation: a role for lipid mediators? Am Rev Respir Dis 136:222-224

27. Jefferies AL, Coates G, O'Brodovich H 1984 Pulmonary epithelial permeability in hyaline membrane disease. N Engl J Med 311:1075-1080

28. Maron MB, Pilati CF 1988 Effect of papaverine on pulmonary vascular permeability to proteins. J Appl Physiol 65:1367-1371

29. Pilati CF, Maron MB 1986 A technique to measure the reflection coefficient using endogenous vascular indicators. Microvasc Res 32:255-260

30. Ripalda MJ, Rudolph N, Wong SL 1989 Developmental patterns of antioxidant defense mechanisms in human erythrocytes. Pediatr Res 26:366-369

31. Winterbourn CC, Stern A 1987 Human red cells scavenge extracellular hydrogen peroxide and inhibit formation of hypochlorous acid and hydroxyl radical J Clin Invest 80:1486-1491

32. Toth KM, Clifford DP, Berger EM, White CW, Repine JE 1984 Intact human erythrocytes prevent $\mathrm{H}_{2} \mathrm{O}_{2}$ mediated damage to isolated perfused rat lungs and cultured bovine pulmonary artery endothelial cells. J Clin Invest 74:292295

33. Seeger W, Suttorp N, Schmidt F, Neuhof H 1986 The glutathione redox cycle as a defense system against hydrogen-peroxide-induced prostanoid formation and vasoconstriction in rabbit lungs. Am Rev Respir Dis 133:1029-1036

34. Tate RM, Vanbenthuysen KM, Shasby DM, McMurtry IF, Repine JE 1982 Oxygen-radical-mediated permeability edema and vasoconstriction in isolated perfused rabbit lungs. Am Rev Respir Dis 126:802-806

35. Patterson GA, Rock P, Mitzner WA, Adkinson Jr NF, Sylvester JT 1985 Effects of imidazole and indomethacin on fluid balance in isolated sheep lungs. J Appl Physiol 58:892-898

36. Ham EA, Egan RW, Soderman DD, Gale PH, Kuehe Jr FA 1979 Peroxidasedependent deactivation of prostacyclin synthetase. J Biol Chem 254:21912194

37. Leffler CW, Hessler JR 1979 Pulmonary and systemic vascular effects of exogenous prostaglandin $I_{2}$ in fetal lambs. Eur J Pharmacol 54:37-42

38. Wolf MB, Watson PD, Scott DRC 1987 Integral-mass balance method for determination of solvent drag reflection coefficient. Am J Physiol 253:H 194204

\section{APPENDIX}

In an isolated organ perfused with recirculating blood, conservation of mass dictates that in the absence of hemolysis or evaporation, the change in perfusate fluid volume over time can be described by the equation

$$
\mathrm{dV}_{\mathrm{w}} / \mathrm{dt}=-\dot{\mathrm{J}}-\dot{\mathrm{Q}}_{\mathrm{L}} \mathrm{F}_{\mathrm{w}}
$$

where $V_{w}$ is equal to the volume of fluid (plasma), $J$ is equal to the volume of plasma filtered across the vascular endothelium per unit time, $\dot{Q}_{L}$ is equal to the volume of blood leaving the system per unit time by leakage or hemorrhage, and $F_{w}$ is equal to the fraction of water in the perfusate.

Because erythrocytes are not filtered and can only leave the system via leakage or hemorrhage, the change in erythrocyte volume over time can be expressed as

$$
\mathrm{dV}_{\mathrm{RBC}} / \mathrm{dt}=-\dot{\mathrm{Q}}_{\mathrm{L}} \mathrm{F}_{\mathrm{RBC}}
$$

where $V_{R B C}$ is equal to the volume of erythrocytes and $F_{R B C}$ is equal to the fractional volume of erythrocytes in the perfusate.

Because the total volume in the system (V) is equal to the sum of erythrocyte and plasma volumes, we can also state that

$$
\mathrm{V}_{\mathrm{w}}=\mathrm{VF}_{\mathrm{w}}
$$

and

$$
\mathrm{dV}_{\mathrm{w}} / \mathrm{dt}=\mathrm{V} \mathrm{dF} \mathrm{w}_{\mathrm{w}} / \mathrm{dt}+\mathrm{F}_{\mathrm{w}} \mathrm{dV} / \mathrm{dt}=-\dot{\mathrm{J}}-\dot{\mathrm{Q}}_{\mathrm{L}} \mathrm{F}_{\mathrm{w}},
$$

Because $\mathrm{V}$ can also described by the equation

$$
\mathrm{V}=\mathrm{V}_{0}-\left(\dot{\mathrm{J}}+\dot{\mathrm{Q}}_{\mathrm{L}}\right) \mathrm{t}
$$

where $V_{0}$ is equal to the initial perfusate volume and $t$ is equal to time,

$$
\mathrm{dV} / \mathrm{dt}=-\left(\dot{\mathrm{J}}+\dot{\mathrm{Q}}_{\mathrm{L}}\right)
$$


Also, because

$$
F_{w}+F_{R B C}=1
$$

then

$$
\mathrm{dF}_{\mathrm{w}} / \mathrm{dt}=-\mathrm{dF}_{\mathrm{RBC}} / \mathrm{dt}
$$

Substituting equations 6 and 8 into equation 4 , we obtain the relation

$$
-\mathrm{dF}_{\mathrm{RBC}} / \mathrm{F}_{\mathrm{RBC}}=\left[\dot{\mathrm{J}} /\left(\dot{\mathrm{J}}+\dot{\mathrm{Q}}_{\mathrm{L}}\right)\right] \mathrm{dV} / \mathrm{V},
$$

which can then be integrated to yield the relation

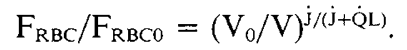

This equation confirms that the change in hematocrit over time is a function only of $\dot{J}$ and $\dot{Q}_{L}$.

The quantity of protein in the perfusate at any given time can be described as

$$
\mathrm{q}=\mathrm{V}_{\mathrm{w}} \mathrm{C}
$$

where $\mathrm{q}$ is the quantity of protein and $\mathrm{C}$ is the concentration of protein in the plasma. Then,

$$
\mathrm{dq} / \mathrm{dt}=\mathrm{V}_{\mathrm{w}} \mathrm{dC} / \mathrm{dt}+\mathrm{C} \mathrm{dV}_{\mathrm{w}} / \mathrm{dt} \text {. }
$$

At sufficiently high filtration rates, the contribution of diffusion to transvascular protein flux becomes insignificant and $\mathrm{dq} / \mathrm{dt}$ can be expressed as

$$
\mathrm{dq} / \mathrm{dt}=-\dot{\mathrm{J}}(1-\sigma) \mathrm{C}-\dot{\mathrm{Q}}_{\mathrm{L}} \mathrm{F}_{\mathrm{w}} \mathrm{C}
$$

where $\sigma$ is equal to the osmotic reflection coefficient for the protein of interest. Combining equations 12 and 13 and substituting $\mathrm{dV}_{\mathrm{w}} / \mathrm{dt}$ from equation 1 and $\mathrm{dt}$ from equation 6 , we obtain the relation

$$
\mathrm{dC} / \mathrm{C}=\left[-\dot{\mathrm{J}}_{\sigma} /\left(\dot{\mathrm{J}}+\dot{\mathrm{Q}}_{\mathrm{L}}\right)\right]\left(1-\mathrm{F}_{\mathrm{RBC}}\right)^{-1}(\mathrm{dV} / \mathrm{V}) .
$$

Solving equation 10 for $F_{\mathrm{RBC}}$, substituting and integrating, we obtain:

$$
\left.\ln \mathrm{C}_{\mathrm{t}} / \mathrm{C}_{0}=\sigma \ln \left[\mathrm{F}_{\mathrm{RBC}_{0}}^{-1}-1\right) /\left(\mathrm{F}_{\mathrm{RBC}_{\mathrm{t}}}^{-1}-1\right)\right],
$$

or

$$
\sigma=\ln \left(\mathrm{C}_{\mathrm{t}} / \mathrm{C}_{0}\right) / \ln \left[\left(\mathrm{F}_{\mathrm{RBC}_{0}}{ }^{-1}-1\right) /\left(\mathrm{F}_{\mathrm{RBC}_{1}}^{-1}-1\right)\right] .
$$

Because $F_{R B C}$ is the same as hematocrit $(\mathrm{Hct})$, equation 16 can be rewritten:

$$
\sigma=\ln \left(\mathrm{C}_{\mathrm{t}} / \mathrm{C}_{0}\right) / \ln \left[\left(\mathrm{Hct}_{0}^{-1}-1\right) /\left(\mathrm{Hct}_{\mathrm{t}}^{-1}-1\right)\right] .
$$

